\title{
The effect of epidermal growth factor on brush border surface area and function in the distal remnant following resection in the rabbit
}

\author{
J A Hardin, B Chung, E V O’Loughlin, D G Gall
}

\begin{abstract}
Background-Epidermal growth factor (EGF) has been shown to increase intestinal absorptive surface area and transport function in normal animals.

Aims-To examine the effect of EGF on absorptive surface area and brush border membrane function in a model of massive small bowel resection.

Methods-New Zealand white rabbits were randomised into two groups: a resected group ( $60 \%$ proximal small bowel resection); and an unmanipulated control group. Distal remnant tissue was examined 10 and 21 days postsurgery. In separate experiments oral EGF $(40 \mu \mathrm{g} / \mathrm{kg} /$ day) was administered to resected animals from days 3 to 8 and animals were studied on day 10.
\end{abstract}

Results-Ten days postsurgery brush border surface area and total absorptive surface area were significantly increased in remnant tissue while brush border membrane vesicle (BBMV) glucose uptake was significantly decreased compared with controls. By 21 days brush border surface area returned to control levels though BBMV glucose uptake remained depressed. EGF treatment induced a further increase in brush border surface area in remnant intestine but did not alter BBMV glucose uptake.

Conclusions-Surgical resection results in significant elevations in absorptive surface area coupled with a decrease in brush border membrane transport function distal to the site of anastomosis. EGF enhances glucose uptake in remnant intestine via recruitment of additional microvillus membrane into the brush border.

(Gut 1999;44:26-32)

Keywords: short gut; resection; surface area; brush border membrane

Department of

oenterology,

Royal Alexandria

Hospital for Children,

Westmead, New South

Wales, Australia

E V O'Loughlin

Correspondence to: Dr D G Gall, Department of Pediatrics, Faculty of Medicine, University of Calgary, 3330 Hospital Dr NW, Calgary, Alberta T2N 4N1, Canada.

Accepted for publication 10 August 1998 between brush border surface area and absorptive function. In a number of disease models, malabsorption was found to be associated with a decrease in brush border surface area. ${ }^{1-3}$ Conversely, in animals of desert origin, enhanced absorptive capacity is associated with a greatly enhanced brush border surface area when compared with animals of non-desert origin. ${ }^{4}$ Furthermore, epidermal growth factor (EGF) has been shown to stimulate an increase in glucose absorption both in vivo and in vitro ${ }^{5}$ that occurs in conjunction with an increase in brush border surface area. $^{6}$

Following massive proximal small bowel resection the distal remnant undergoes a number of compensatory changes. Mucosal hyperplasia coupled with luminal dilatation of the intestinal remnant has been reported to result in an almost fourfold increase in absorptive surface area. ${ }^{78}$ Functional alterations have also been reported in the short gut. An increase in in vivo glucose absorption has been reported in a number of studies ${ }^{79}$ but when normalised to mucosal weight transport values were not found to differ from those of controls. ${ }^{7}$ In short circuited tissue $\mathrm{Na}^{+}$coupled glucose absorption per $\mathrm{cm}^{2}$ has been reported both to increase ${ }^{10}$ in the absence of any alteration in electrolyte transport in a rat model, and decrease $^{11}$ in a rabbit model of massive small bowel resection. Results obtained in studies examining $\mathrm{Na}^{+}$coupled glucose uptake in isolated brush border membrane vesicle (BBMV) preparations from the distal remnant have varied depending on the model and time of study postsurgery, either showing no alteration in glucose uptake kinetics ${ }^{12}$ or a late induction of transport capacity. ${ }^{13}$

Due to its well described effects on intestinal epithelial cell proliferation a number of laboratories have investigated the therapeutic potential of EGF in remnant intestine with conflicting results. ${ }^{14-16}$ Previous studies in our laboratories showed that orogastric EGF treatment for five days postsurgery significantly improved digestive and absorptive function in intact remnant tissue 10 days following massive small bowel resection. ${ }^{11}$

This study examines the relation between microvillus membrane glucose kinetics and absorptive surface area in the ileum of unmanipulated controls and the distal remnant in rabbits 10 and 21 days following massive small bowel resection, to determine whether incorporation of transport proteins into microvillus membrane and insertion of new membrane (increase in brush border surface area) are directly linked. It also investigates the mechanisms behind the observed therapeutic benefit following EGF treatment of resected animals.

Previous work has suggested a correlation
Abbreviations used in this paper: BBMV, brush border membrane vesicle; EGF, epidermal growth factor; BrdU, bromodeoxyuridine; TMA-DPH, 1-[4-(trimethylamino)phenyl]-6-phenylhexatriene; DMSO, dimethyl sulphoxide; RES, resected; CON, control; SGLT, sodium glucose linked transporter. 
Materials and methods

ANIMAL MODEL

New Zealand White rabbits weighing 800 $1200 \mathrm{~g}$ were used. Animals were randomised into control and resected groups. Weight and age matched unmanipulated animals were used as controls. Surgery was performed on the resected animals under general anaesthesia using halothane. Sixty per cent of proximal small bowel was resected from $10 \mathrm{~cm}$ distal to the ligament of Treitz to $25 \mathrm{~cm}$ proximal to the ileocaecal valve and an end to end anastomosis performed. Animals undergoing surgery were given $1 \mathrm{ml} / \mathrm{kg}$ Penlong (Rogar/STB Inc., London, Ontario, Canada) intraperitoneally immediately postsurgery and a second injection of $1 \mathrm{ml} / \mathrm{kg}$ Penlong intramuscularly 24 hours later. Postoperatively, animals were allowed free access to water and food was reintroduced 24 hours postsurgery. Studies were performed 10 and 21 days postsurgery. In a second series of experiments, animals that underwent resection received orogastric EGF $40 \mu \mathrm{g} / \mathrm{kg} /$ day (human recombinant EGF, amino acids 1-52, Austral Biologicals, San Ramone, California, USA) in saline from day 3 to day 8 postsurgery and were studied on day 10 . Animals were weighed daily and observed for the presence of diarrhoea. All groups were studied concurrently. Animal care and experimental procedures followed the guidelines of the Canadian Council of Animal Care.

\section{MEASUREMENTS}

On the day of study, animals were killed by an intravenous injection of sodium pentobarbitol (Euthanyl, MTC Pharmaceuticals, Cambridge, Ontario, Canada) and $10 \mathrm{~cm}$ of ileum, starting $4 \mathrm{~cm}$ distal to the site of anastomosis, was removed and flushed with cold Krebs buffer. A $2 \mathrm{~cm}$ segment was fixed for light microscopy; the remaining length was measured, scraped of mucosa with a glass slide, and the mucosa subsequently weighed, homogenised in $2.5 \mathrm{mM}$ EDTA and flash frozen at $-70^{\circ} \mathrm{C}$ until analysed for $\mathrm{DNA}^{17}$ and protein ${ }^{18}$ by established techniques.

SURFACE AREA DETERMINATION

Analysis of all morphological data was performed in a blind manner to prevent observer bias. In separate experiments, mucosal architecture was examined by light microscopy, brush border surface area was determined by electron microscopy, or total absorptive surface area was assessed by TMA-DPH equilibration (see below) in 10 and 21 day resected animals, 10 day resected + EGF animals, and 10 and 21 day controls. All microscopy specimens were obtained from the first $2 \mathrm{~cm}$ of ileum starting 4 $\mathrm{cm}$ distal to the site of anastomosis or the corresponding site from control animals. Epithelial cell kinetics were assessed in 10 day resected, 10 day control, and 10 day resected + EGF animals.

Light microscopy

Tissue was fixed for at least 24 hours in Carnoy's solution at room temperature, dehydrated, embedded in paraffin wax, and sectioned. Sections were stained with haematoxy- lin and eosin for morphometric analysis and measurement of epithelial thickness (villus height plus crypt depth). Enterocyte migration rate was determined by an immunoperoxidase staining technique as previously described. ${ }^{3}$ Briefly, animals were given an intraperitoneal injection of $100 \mathrm{mg}$ of bromodeoxyuridine (BrdU; Sigma, Grade V) per gram body weight and killed 16 or 24 hours later. Tissue was fixed as described above and sectioned. Sections were hydrolysed in $1 \mathrm{M} \mathrm{HCl}$ for 50 minutes at $37^{\circ} \mathrm{C}$ to expose antigenic determinants on DNA and then blocked with $20 \%$ goat serum in phosphate buffered saline to reduce background staining. Sections were then treated with a $1 / 30$ dilution of the primary antibody (anti-BrdU, Becton-Dickinson, catalogue no. 347580) followed by a $1 / 100$ dilution of the secondary antibody (Vectastain ABC Kit, Dimension Lab Inc., catalogue no. PK-6102). Ten well oriented crypt-villus units were examined per slide using a Leitz Wetzlar microscope.

\section{Transmission electron microscopy}

Brush border surface area was assessed in tissue obtained from three animals in each group. Animals were killed by injection with euthanyl and $2 \mathrm{~cm}$ of tissue was removed and fixed in 5\% gluteraldehyde in $0.1 \mathrm{M}$ cacodylate buffer, $\mathrm{pH} 7.2$, osmolality $300 \mathrm{mOsmol}$ at $20^{\circ} \mathrm{C}$. Specimens were postfixed in $1 \% \mathrm{OsO}_{4}$, dehydrated in distilled alcohol, cleared with propylene oxide, and infiltrated with and embedded in Spurr's low viscosity medium (JB EM Services Inc., Dorval). Thin sections were double stained with saturated uranyl acetate in $50 \%$ ethanol and $0.4 \%$ lead citrate. ${ }^{19}$ Micrographs of the same magnification were obtained from the mid-villus region of the sections as determined by a low magnification observation of complete villi. Mid-villus brush border surface area was calculated as previously described ${ }^{1}$ by a method involving the measurement of the variable parameters of height, width, and density of microvilli. Briefly, the number of microvilli over a $2 \mu \mathrm{m}$ length of cell surface was counted and divided by the cell surface length to give the number per micron. This value was squared to give the number of microvilli per square micron of cell surface. Along the same cell length the height and width of microvilli were measured. Microvilli were assumed to approximate a cylinder with a flat cap. Thus, from the mean height and width the surface area of microvilli was calculated and this value multiplied by the density of microvilli per square micron of cell surface. Duplicate measurements were made and averaged in each micrograph from tissue showing well oriented longitudinal sections of microvilli. All micrographs were coded and measurements were made in a blind fashion.

\section{TMA-DPH equilibration}

The apical membrane surface area of in vivo ileal loops was determined in at least five animals per group by partitioning of the impermeant fluorophore 1-[4-(trimethylamino)phenyl]-6-phenylhexatriene (TMADPH; Molecular Probes, Eugene, Oregon, 
USA) between the apical membrane of enterocytes lining the loops and unsealed erythrocyte ghosts, using a modification of the technique described by Lange and colleagues ${ }^{20}$ as previously reported. ${ }^{6}$ Briefly, animals were anaesthetised with halothane, a laparotomy performed, and an $8-10 \mathrm{~cm}$ blind loop constructed with ligatures starting $4 \mathrm{~cm}$ distal to the site of anastomosis (or the corresponding site in controls). Unsealed erythrocyte ghosts were prepared as described by Steck ${ }^{21}$ and labelled with $10 \mu \mathrm{M}$ TMA-DPH in dimethyl sulphoxide (DMSO). Ghosts were washed several times to remove unbound probe and approximately $260 \times 10^{6}$ ghosts in $2 \mathrm{ml} \mathrm{Krebs}$ buffer $\left(\mathrm{Na}^{+} 140 \mathrm{mM}, \mathrm{Cl}^{-}\right.$ $127.5 \mathrm{mM}, \mathrm{HCO}_{3}{ }^{-} 25 \mathrm{mM}, \mathrm{K}^{+} 10 \mathrm{mM}, \mathrm{Ca}^{2+}$ $1.25 \mathrm{mM}, \mathrm{Mg}^{2+} 1.1 \mathrm{Mm}, \mathrm{H}_{2} \mathrm{PO}_{4} 2 \mathrm{mM}, \mathrm{pH}$ 7.4) injected into the isolated loop. The probe was allowed to equilibrate for 10 minutes, after which the ghosts were removed and measured for total fluorescence and number and the loop excised for determination of length. Total fluorescence was determined by an SLM AMINCO SPF-500C spectrophotometer (Urbana, Illinois, USA). The number and size of the unsealed ghosts was assessed by coulter counter (Model ZM, Coulter Electronics Ltd, Luton, UK) and the surface area per ghost was calculated. Total absorptive surface area was calculated relative to that of red blood cells by assessing the total ghost membrane surface area, the relative partitioning of the fluorescent probe, and the length of the intestinal loop to which the probe was exposed.

\section{TRANSPORT STUDIES}

In separate experiments, mucosa was obtained from the distal remnant of 10 and 21 day resected animals $(n=5), 10$ day resected $+E G F$ animals $(n=5)$, and equivalent tissue in 10 and 21 day control animals $(n=6)$ and brush border membrane vesicles (BBMV) prepared by a calcium chloride precipitation method as previously described. ${ }^{22}$ BBMV were stored in liquid nitrogen until day of assay. To obtain enough membrane to perform the kinetic analysis control animals were twinned, concurrent experiments run, and their mucosa pooled for preparation of brush border membrane vesicles. Resected animals were not twinned as the mucosal yield was sufficient in the distal remnant to provide the amount of brush border membrane necessary. All measurements were normalised to membrane protein content as determined by the method of Lowry et al. ${ }^{23}$ Purity and basolateral contamination of membranes was assessed by determining and comparing sucrase activity, ${ }^{24}$ and $\mathrm{Na}^{+} / \mathrm{K}^{+}$ ATPase ${ }^{25}$ in both the initial mucosal homogenate and microvillus membrane preparations.

Brush border membrane vesicle uptake of D-glucose was assessed using a rapid filtration technique and a five second time course as previously described. ${ }^{26}$ This technique measures the uptake of a standard concentration of tracer in the presence of increasing concentrations of cold substrate and produces more accurate and reproducible transport values than those obtained with older techniques. All chemicals were obtained from Sigma (St Louis, Missouri,
USA), except for the $\mathrm{D}-\left[{ }^{3} \mathrm{H}\right]$-glucose which was obtained from NEN Research Products (DuPont, Mississauga, Ontario, Canada). Vesicles were resuspended to a final protein concentration of $10-15 \mathrm{mg} / \mathrm{ml}$ in $100 \mathrm{mM} \mathrm{KCl}, 300 \mathrm{mM}$ mannitol, and $10 \mathrm{mM}$ Tris-HEPES (pH 7.5). Glucose uptake was initiated by rapidly mixing $10 \mu \mathrm{l}$ vesicles with $50 \mu \mathrm{l}$ buffer containing a concentration of mannitol ranging from 0 to $100 \mathrm{mM}, 100 \mathrm{mM}$ NaSCN, $10 \mathrm{mM}$ TrisHEPES, 100 mM KCl (pH 7.5), $4 \mu \mathrm{M}$ D- $\left[{ }^{3} \mathrm{H}\right]-$ glucose, and variable concentrations of unlabelled D-glucose ranging from 0 to $100 \mathrm{mM}$. The reaction was stopped by addition of $4 \mathrm{ml}$ ice cold stop solution containing $100 \mathrm{mM}$ $\mathrm{NaCl}, 100 \mathrm{mM}$ mannitol, $10 \mathrm{mM}$ Tris-HEPES, and $100 \mathrm{mM} \mathrm{KCl}$ ( $\mathrm{pH} 7.5)$. The reaction solution was then rapidly filtered through a $0.45 \mu \mathrm{m}$ filter (Millipore/Continental Water Systems, Bedford, Massachusetts, USA), washed twice with $3 \mathrm{ml}$ stop solution, and counted in a liquid scintillation counter. The data are expressed as nanomoles of $\mathrm{D}-\left[{ }^{3} \mathrm{H}\right]$ glucose taken up per minute per mg protein.

\section{STATISTICAL ANALYSIS}

Data are expressed as mean (SE) and statistical analyses were performed by Student's $t$ test or analysis of variance with repeated measurements where appropriate. Statistical comparison of kinetic curves was performed as previously described. ${ }^{27}$ Significance levels were set at 0.05 .

\section{Results}

Resected (RES) animals gained significantly less weight than unmanipulated control animals (CON) over the initial 10 day recovery period (CON 382 (23) g, $n=6$ versus RES 102 (22) $\mathrm{g}, \mathrm{n}=10, \mathrm{p}<0.001)$. EGF treatment resulted in a significant increase in weight gain in 10 day resected + EGF animals (184 (14), $\mathrm{n}=16, \mathrm{p}<0.01)$ compared with resection alone although weight gain remained low compared with controls $(p<0.001)$. Massive small bowel resection resulted in the expected stimulation of mucosal growth. Protein (CON 9.6 (2), $n=6$ versus RES 15.6 (5.4) mg protein $/ \mathrm{cm}, \mathrm{n}=7$, $\mathrm{p}<0.05)$ and DNA (CON $0.53(0.09), \mathrm{n}=6$ versus RES $0.89(0.08) \mu \mathrm{g} D \mathrm{DNA} / \mathrm{cm}, \mathrm{n}=9$, $\mathrm{p}<0.05)$ were significantly increased in 10 day resected animals when compared with unmanipulated controls. Protein $(17.3(3.8) \mathrm{mg} / \mathrm{cm}$, $\mathrm{n}=7, \mathrm{p}<0.01)$ and DNA $(1.18(0.24) \mu \mathrm{g} / \mathrm{cm}$, $\mathrm{n}=7, \mathrm{p}<0.01)$ values remained elevated in the 10 day resected + EGF group compared with 10 day control animals. DNA content was also significantly elevated in the 10 day resected + EGF group compared with 10 day resected animals $(\mathrm{p}<0.05)$, while protein measurements did not differ. Table 1 shows mucosal wet weight values. Mucosal wet weight was significantly increased in 10 day resected and 10 day resected + EGF animals compared with unmanipulated controls. At 21 days postsurgery mucosal wet weight values remained significantly elevated in remnant tissue compared with control. 
Table 1 Mucosal thickness and wet weight in 21 day control and resected animals and 10 day control, resected and epidermal growth factor (EGF) treated resected animals

\begin{tabular}{lll}
\hline & Mucosal thickness $(\mu \mathrm{m})$ & Wet weight $(\mathrm{g} / \mathrm{cm})$ \\
\hline 10 days & $459(12)(\mathrm{n}=18)$ & $1.08(0.21)(\mathrm{n}=6)$ \\
$\quad$ Control & $654(30)(\mathrm{n}=9)^{\star}$ & $1.79(0.51)(\mathrm{n}=7)^{\star}$ \\
$\quad$ Resected & $630(27)(\mathrm{n}=10)^{\star}$ & $1.76(0.36)(\mathrm{n}=11)^{\star \star}$ \\
$\quad \begin{array}{l}\text { Resected + EGF } \\
21 \text { days }\end{array}$ & $494(13)(\mathrm{n}=10)$ & $1.28(0.23)(\mathrm{n}=6)$ \\
$\quad$ Control & $689(18)(\mathrm{n}=7)^{\star \star}$ & $2.28(0.46)(\mathrm{n}=9)^{\star \star}$ \\
$\quad$ Resected &
\end{tabular}

${ }^{\star} \mathrm{p}<0.05 v$ control; ${ }^{\star \star} \mathrm{p}<0.01 v$ control.

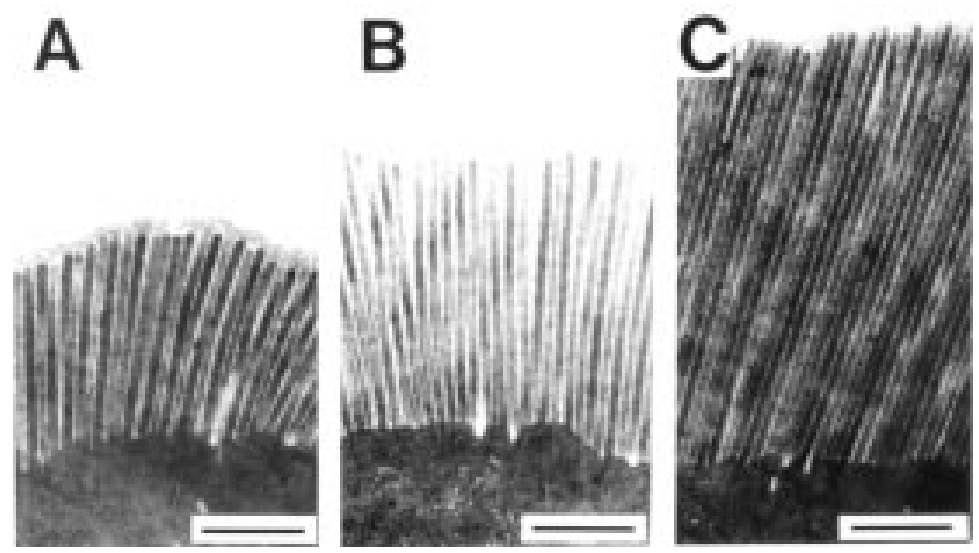

Figure 1 Representative photomicrographs from the mid-villus region in (A) control, (B) resected, and $(C)$ resected $+E G F$ tissue. Tissue appeared ultrastructurally normal. Bar $=1$ $\mu m$.

MORPHOLOGY

By light microscopy intestinal sections from all five groups of animals appeared normal. Enterocytes were of normal appearance, there was no evidence of epithelial damage, and crypt/ villus architecture was unaltered. When quantitative measurements were made epithelial thickness was found to be significantly greater $(\mathrm{p}<0.05)$ in tissue from 10 day resected and 10 day resected + EGF animals compared with

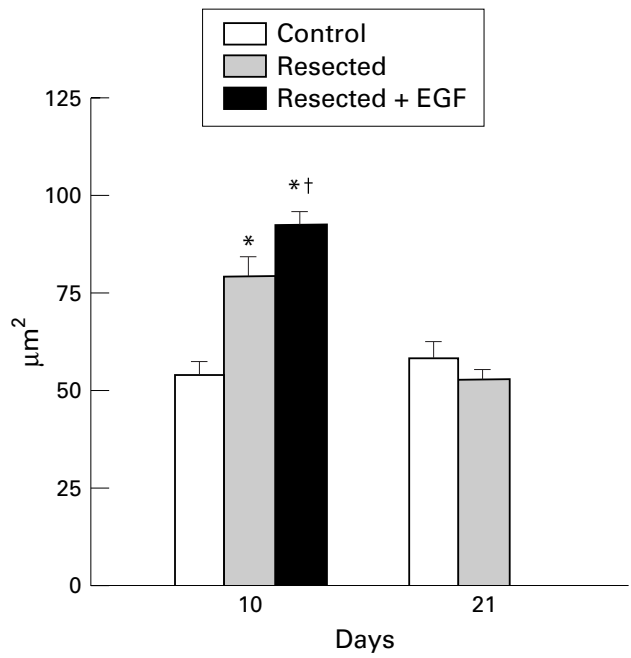

Figure 2 Mid-villus brush border surface area measurements in tissue from 10 day control $(n=26$ photomicrographs obtained from three animals), 10 day resected ( $n=29$ photomicrographs from three animals), resected $+E G F$ ( $n=41$ photomicrographs from three animals), 21 day control ( $n=40$ photomicrographs from three animals), and 21 day resected $(n=30$ photomicrographs from three animals) animals. ${ }^{\star} p<0.001$ compared with control; $t p<0.05$ compared with 10 day resected group. Data represent mean (SE). controls (table 1). At 21 days postresection epithelial thickness remained significantly $(p<0.01)$ increased over controls. Epithelial thickness did not differ between 10 and 21 day control tissue or 10 and 21 day resected animals or between 10 day resected and 10 day resected $+\mathrm{EGF}$ animals. Tissue from 10 day resected animals (RES $30.5 \quad(6.3), n=6)$ showed a significant $(\mathrm{p}<0.01)$ increase in villus enterocyte migration rate over that seen in controls (5.3 (1.7) $\mu \mathrm{m} / \mathrm{h}, \mathrm{n}=5)$ ). In EGF treated animals (RES + EGF 5.9 (1.4), n=4) enterocyte migration rate returned to control levels and was significantly $(p<0.01)$ less than that seen in 10 day resected animals. Figure 1 shows representative electron photomicrographs of tissue from 10 day control, 10 day resected, and 10 day resected + EGF animals. The general appearance of enterocytes from all five groups was similar. No ultrastructural abnormalities were noted in any of the groups. Cell membranes and cellular organelles appeared normal. Microvilli appeared normal and of equal numbers and density. The striking difference was the increase in microvillus height observed in tissue from 10 day resected animals compared with controls and the further increase in microvillus height observed in 10 day resected + EGF animals compared with both 10 day resected and control groups (see below).

\section{SURFACE AREA DETERMINATION}

Figure 2 shows mid-villus brush border surface area. Brush border surface area in tissue from 10 day resected animals was increased by $46 \%$ over that seen in control tissue $(\mathrm{p}<0.001)$. Brush border surface area was further increased in the resected + EGF group compared with the 10 day resected group $(16 \%, \mathrm{p}<0.05)$ and with controls $(70 \%, \mathrm{p}<0.001)$. Brush border surface area did not differ between control and resected animals 21 days postsurgery. The increase in brush border surface area in resected animals was due to a significant $(\mathrm{p}<0.001)$ increase in microvillus height $(3.1$ (0.1) $\mu \mathrm{m}, \mathrm{n}=29$, photomicrographs from three animals) compared with controls (2.3 (0.1) $\mu \mathrm{m}, \mathrm{n}=26$, from three animals). Number of microvilli per $\mu \mathrm{m}$ cell surface (RES $8.7(0.2)$ versus CON $9.0(0.2)$ ) and microvillus width (RES $0.052 \quad(0.001)$ versus CON 0.052 $(0.001) \mu \mathrm{m})$ did not differ. The additional increase in brush border surface area seen in 10 day resected + EGF treated tissue was primarily due to a further increase in microvillus height in EGF treated tissue (3.5 (0.1) $\mu \mathrm{m}$, $\mathrm{n}=42$ from three animals) compared with tissue from 10 day resected $(\mathrm{p}<0.05)$ and control animals $(p<0.001)$. Number of microvilli per $\mu \mathrm{m}$ cell surface was also increased in 10 day resected + EGF animals (9.6 (0.2)) compared with the 10 day resected group $(\mathrm{p}<0.01)$, but microvillus width was decreased $(\mathrm{p}<0.001)$ in the 10 day resected + EGF group (0.045 (0.001) $\mu \mathrm{m})$ compared with both 10 day resected and 10 day control animals. Figure 3 shows the data from experiments examining total surface area per $\mathrm{cm}$ intestinal length as assessed by TMA-DPH equilibration. Total 
Table 2 Brush border membrane vesicle (BBMV) glucose transport kinetic parameters at 10 and 21 days

\begin{tabular}{lll}
\hline & $V_{\max }($ nmol/min/mg protein) & $K_{m}(\mu m)$ \\
\hline 10 days & $19.2(1.2)$ & $118(11)$ \\
Control (n=6) & $12.9(1.2)^{\star \star \star}$ & $139(18)$ \\
Resected (n=5) & $8.9(0.7)^{\star \star \star}$ & $145(17)$ \\
Resected + EGF (n=5) & $17.2(0.7)$ & $130(9)$ \\
21 days & $12.1(0.8)^{\star \star \star}$ & $166(21)$ \\
$\quad$ Control (n=6) & Resected (n=5) & \\
\hline
\end{tabular}

EGF, epidermal growth factor; $n$, number of BBMV preparations (see methods). $\star \star \star \mathrm{p}<0.001 v$ control. significant increase in enterocyte migration rate, epithelial thickness, brush border surface area, and total absorptive surface area. Recruitment of microvillus membrane appears to be an early adaptation following intestinal resection. Brush border surface area was increased 10 days postresection, but returned to control levels at 21 days postresection. The increase in brush border surface area observed in the 10 day resected group and the 10 day resected + EGF group was due primarily to a significant increase in microvillus height. Alterations in microvillus height appear to be a common mechanism whereby brush border surface area is regulated. Brush border surface area alterations due to changes in microvillus height have been previously noted in a number of models. ${ }^{126}$ Indeed, a similar increase in brush border surface area due to an increase in microvillus height has been reported in a rat model of proximal small bowel resection eight weeks postsurgery. ${ }^{10}$ In contrast, Zeitz and colleagues $^{28}$ showed a significant decrease in brush border surface area in rats two, six, and 12 days postresection. The reason for this discrepancy is not clear but may be the result of differences in species and study design.

Under normal physiological conditions EGF is preserved in the intestinal lumen. EGF is relatively acid stable and under intermediate acidic conditions passes through the stomach largely intact. ${ }^{29}$ Furthermore, EGF is resistant to digestion by pancreatic enzymes in the presence of food proteins. ${ }^{30}$ In the current study rabbits were given ad libitum access to food, and thus likely always had dietary protein present in their stomachs.

Weight gain was decreased in resected animals at 10 days compared with age matched unmanipulated controls. Previous studies have shown that malnutrition leads to increased brush border surface area. ${ }^{2}$ Thus, the reduced weight gain in resected animals may provide a similar signal leading to increased absorptive surface area. EGF treatment significantly increased weight gain in resected animals over non-treated resected animals. This finding correlates with the increase in remnant functional capacity seen following EGF treatment and provides further evidence for a therapeutic role for EGF in the treatment of short gut.

Total surface area measured by TMA-DPH equilibration was increased at both 10 and 21 days postresection. This direct measurement of total absorptive surface area supports earlier findings of up to a fourfold increase in total mucosal surface area in the distal remnant following surgical resection. ${ }^{81}$ Despite the increase in brush border and total surface area, $\mathrm{V}_{\max }$ for glucose uptake in BBMV from the distal remnant was significantly $(p<0.001)$ decreased in the 10 day resected group compared with control values. This down regulation of transporters does not appear to be due to a lack of transporter message. Recent reports have shown an increase in $\mathrm{Na}^{+}$dependent glucose cotransporter mRNA in remnant intestine. ${ }^{32}$ The defect may potentially lie at the level of translation of the message or, alternatively, in the insertion of transporter protein into microvillus

\section{Discussion}

As we have previously reported ${ }^{11}$ remnant intestine exhibited hyperplasia 10 days postresection. In the current study, cellular hyperplasia was shown to be associated with a 
membrane prior to recruitment into the brush border. The notable increase in enterocyte migration rate in the 10 day resected group may provide an explanation. The rapid enterocyte turnover may not allow sufficient time for insertion of sodium glucose linked transporter (SGLT) 1 into the apical membrane. A similar phenomenon has been observed in models of viral enteritis. Infection with transmissible gastroenteritis virus ${ }^{33}$ or rotavirus ${ }^{34}$ leads to loss of mature enterocytes and an increase in enterocyte migration rate resulting in an epithelium composed of immature crypt like cells that fail to express SGLT1.

By 21 days postsurgery brush border surface area in the distal remnant returns to control levels. Total absorptive surface area remains significantly elevated over controls, however, due to the persistent increase in epithelial thickness at 21 days and the large dilatation of the remnant lumen. The $V_{\max }$ for BBMV glucose uptake remains significantly decreased compared with controls at 21 days. These findings are in agreement with our earlier observations in which glucose transport was decreased in intact remnant tissue at 21 days. ${ }^{11}$

Reported measurements of transport function in the short gut have varied widely. An increase in in vivo glucose absorption per $\mathrm{cm}$ intestinal length has been shown in a number of studies ${ }^{7}{ }^{9}$ but when normalised to mucosal weight transport values did not differ from controls. ${ }^{7}$ In vitro, active D-glucose uptake was found not to differ in ileal tissue from transected controls and resected animals. ${ }^{31}$ In short circuited tissue $\mathrm{Na}^{+}$coupled glucose absorption per $\mathrm{cm}^{2}$ surface area has been reported to increase $\mathrm{e}^{10}$ in the absence of any alteration in electrolyte transport in a rat model while $\mathrm{Na}^{+}$coupled alanine transport has been shown to decrease in the intestinal remnant when expressed per $\mathrm{cm}^{2}$ surface area. ${ }^{35}$ Menge and colleagues ${ }^{12}$ in a rat model reported no alteration in BBMV glucose kinetics between resected and unmanipulated controls. These studies were carried out four weeks postresection which may have allowed for additional adaptation. Other investigators found negligible sodium dependent D-glucose transport in the distal ileum of control rats, rats two weeks after resection, and rats two or six weeks after transection. ${ }^{13}$ In this latter study an induction of sodium dependent glucose transport was seen in experimental animals six weeks postresection. The findings suggest that remnant intestine undergoes a number of adaptive changes including a massive upregulation of absorptive surface area per $\mathrm{cm}$ length of bowel resulting in either an increase, no change, or a decrease in absorptive capacity per square area depending on animal species, time of sampling postresection, and transport ligand studied. In a recent study ${ }^{11}$ we showed a decrease in short circuited 3-0-methyl glucose transport per $\mathrm{cm}^{2}$ surface area and a concurrent decrease in phlorizin specific binding sites in the ileal remnant following resection compared with controls in this rabbit model of massive small bowel resection. These findings are supported by the current work in which BBMV glucose uptake was also decreased in the resected group compared with controls.

Observations of intestinal adaptation following resection provide insights into the regulation of membrane in the brush border. We have previously reported a direct correlation between brush border surface area and glucose and amino acid absorption both under normal physiological conditions ${ }^{4}$ and during disease states. ${ }^{1-3}$ EGF induced increases in absorptive surface area correlate with increased rates of nutrient transport in the intact animal as well as in short circuited tissue $\mathrm{e}^{5}$ and isolated brush border membrane vesicles. ${ }^{36}$ Additionally, studies suggest that the apical membrane that is recruited in response to EGF exposure comes from a preformed pool as no difference could be seen in microvillus membrane lipid composition or sucrase activity in tissue exposed to EGF and control tissue. ${ }^{6}$ These findings suggest that the recruitment of preformed microvillus membrane and the insertion of transport proteins such as SGLT1 occur in parallel and are linked processes. In contrast, the data from the current study show that recruitment of brush border membrane can occur in conjunction with a decrease in absorptive function per unit of membrane protein. This dissociation of membrane recruitment and insertion of transport proteins in the brush border of the remnant intestine suggest that these processes are separate and distinct and may be under different regulatory control mechanisms.

In the present study EGF treatment induced a further increase in brush border surface in remnant tissue but the $V_{\max }$ for glucose uptake in microvillus membrane remained depressed. In an earlier study in the same animal model, EGF treatment following resection caused a substantial increase in glucose absorption and phlorizin binding, a marker of SGLT1, in intact tissue. ${ }^{11}$ How then does one reconcile the observations of EGF induced increases in glucose transport in intact tissue after resection with the current data showing no change in BBMV glucose uptake in the 10 day resected group treated with EGF? There are two potential mechanisms that could account for an increase in glucose transport without a corresponding increase in glucose transport protein, SGLT1, density in microvillus membrane: (1) an overall increase in brush border membrane with transporter density remaining the same per $\mathrm{mg}$ of membrane protein; and/or (2) alterations in the geographical distribution of SGLT1 such that it is expressed in the microvillus membrane in enterocytes lower on the villus, regions which normally do not express SGLT1. The latter suggestion has been observed in rats made diabetic by streptozotocin treatment. Control rats express SGLT1 on enterocytes on the top third of villus. Induction of diabetes increased glucose absorption and expression of SGLT1 in cells in the middle third of the villus. ${ }^{37}$ In resected animals treated with EGF an overall increase in total brush border surface area with maintained density of the transporter appears to be at least part of the explanation for normalisation of glucose 
transport. EGF treatment caused a further increase in brush border surface area and total mucosal surface area compared with resection alone. However, a comparison of the magnitude of the functional defect previously reported in remnant tissue (greater than threefold decrease in glucose transport) ${ }^{11}$ with the overall increase in brush border surface area shown following EGF treatment suggests recruitment of additional brush border membrane does not completely account for the recovery of transport function. The recovery of glucose uptake seen in intact remnant tissue following EGF treatment is probably due to several factors: recruitment of additional brush border and thus an increase in the absolute numbers of transport proteins; a reduction in the enterocyte; migration rate leading to increased maturation of transporting villus enterocytes; and possibly an alteration in the geographical distribution of SGLT1 protein along the crypt-villus axis.

In summary, the findings indicate that surgical resection results in a significant increase in absorptive surface area coupled with a decrease in brush border membrane transport function distal to the site of anastomosis. EGF treatment stimulates recovery of transport function in the distal remnant via the recruitment of additional microvillus membrane into the brush border of villus enterocytes.

This work was supported by a grant from the Medical Research Council of Canada and the Children's Hospital Fund, Camperdown, New South Wales, Australia.

1 Buret A, Gall DG, Olson ME. Growth, activities of enzymes in the small intestine, and ultrastructure of microvillus border in gerbils infected with Giardia duodenalis. Parasitol Res 1991;77:109-14.

2 Buret A, O'Loughlin EV, Curtis G, et al. Effect of acute Yersinia enterocolitica infection on small intestinal ulYersinia enterocolitica infection on small inte
trastructure. Gastroenterology 1990;98:1401-7.

3 Curtis GH, Patrick MK, Catto-Smith AG, et al. Intestinal anaphylaxis in the rat. Gastroenterology 1990;98:1558-66.

4 Buret A, Hardin J, Olson ME, et al. Adaptation of the small intestine in desert-dwelling animals: morphology, ultrastructure and electrolyte transport in the jejunum of rabbits, rats, gerbils and sand rats. Comp Biochem Physio [A] 1993;105A:157-63.

5 Opleta-Madsen K, Hardin J, Gall DG. Epidermal growth factor upregulates intestinal electrolyte and nutrient transport. Am F Physiol 1991;260:G807-14.

6 Hardin JA, Buret A, Meddings JB, et al. Effect of epidermal growth factor on enterocyte brush-border surface area. An f Physiol 1993;264:G312-18.

7 Feldman EJ, Dowling RH, McNaughton J, et al. Effects of oral versus intravenous nutrition on intestinal adaptation after small bowel resection in the dog. Gastroenterology 1976;70:712-19.

8 Vanderhoof JA, Langnas AN, Pinch LW, et al. Short bowel vandrome. $\mathcal{F}$ Pediatr Gastroenterol Nutr 1992;14:359-70.

9 Dowling RH, Booth CC. Structural and functional changes following small intestinal resection in the rat. Clin Sci 1967; 32:139-49.

10 Schulzke J-D, Fromm M, Bentzel CJ, et al. Ion transport in the experimental short bowel syndrome of the rat. Gastroenterology 1992;102:497-504

11 O'Loughlin EV, Winter M, Shun A, et al. Structural and functional adaptation following jejunal resection in rabbits: effect of epidermal growth factor. Gastroenterology 1994 107:87-93.
12 Menge H, Murer H, Robinson JWL. Glucose transport by brush-border membrane vesicles after proximal resection or ileo-jejunal transposition in the rat. $\mathscr{f}$ Physiol 1978;274: $9-16$

13 Freeman HJ, Ellis ST, Johnston GA, et al. Sodiumdependent D-glucose transport after proximal small intestinal resection in rat. Am F Physiol 1988;255:G292-7.

14 Chaet MS, Arya G, Ziegler MM, et al. Epidermal growth factor enhances intestinal adaptation after massive small bowel resection. F Pediatr Surg 1994;29:1035-9.

15 Goodlad RA, Savage AP, Lenton W, et al. Does resection enhance the response of the intestine to urogastroneepidermal growth factor in the rat. Clin Sci 1988;75:121-6.

16 Thompson JS, Bragg LE, Saxena SK. The effect of intestinal resection and urogastrone on intestinal regeneration. Arch Surg 1990;125:1617-21.

17 Hinegardner R. An improved fluorometric assay for DNA. Anal Biochem 1971;39:197-201.

18 Bradford MM. A rapid and sensitive method for the quantitation of microgram quantities of protein utilizing the principle of protein-dye binding. Anal Biochem 1976;72:24854

19 Venable JH, Coggeshall R. A simplified lead citrate stain for use in electron microscopy. F Cell Biol 1965;25:407-8.

20 Lange Y, Swaisgood MH, Ramos BV, et al. Plasma membranes contain half the phospholipid and $90 \%$ of the cholesterol and sphingomyelin in cultured human fibroblasts. F Biol Chem 1989;264:3786-93.

21 Steck TL. Preparation of impermeable inside-out and rightside out vesicles from erythrocyte membranes. In: Korn $\mathrm{ED}$, ed. Methods in membrane biology. New York: Plenum Press, 1974:245.

22 Kessler M, Acuto O, Storelli C, et al. A modified procedure for the rapid preparation of efficiently transporting vesicles from small intestinal brush border membranes. Their use in investigating some properties of D-glucose and choline transport systems. Biochim Biophys Acta 1978;771:35-41.

23 Lowry OH, Rosebrough NJ, Farr AL, et al. Protein measurement with the Folin phenol reagent. F Biol Chem 1951;193:265-75.

24 Dalquist A. Method for assay of intestinal dissacharidases. Anal Biochem 1964;7:18-25.

25 Kelly M, Butler DG, Hamilton JR. Transmissable gastroenteritis in piglets: a model of infantile viral diarrhea. $\mathcal{F}$ Pediatr 1972;80:925-31.

26 Malo C, Berteloot A. Analysis of kinetic curves in transport studies: new insights from kinetic studies of $\mathrm{Na}^{+}$-D-glucose cotransport in human intestinal brush-border membrane vesicles using a fast sampling, rapid filtration apparatus. $\mathcal{F}$ Membr Biol 1991:122:127-41.

27 Meddings JB, Scott RB, Fick GH. Analysis and comparison of sigmoidal curves: application to dose-response data. $\mathrm{Am}$ f Physiol 1989;257:G982-9.

28 Zeitz M, Menge H, Riecken EO. Early ultrastructural adaptive changes of ileal enterocytes after proximal small bowel resection as determined morphometrically. Res Exp Med 1985;185:259-68.

29 Playford RJ, Marchbank T, Calnan DP, et al. Epidermal growth factor is digested to smaller, less active forms in acidic gastric juice. Gastroenterology 1995;108:92-101.

30 Playford RJ, Woodman AC, Clark P, et al. Effect of luminal growth factor preservation on intestinal growth. Lancet 1993;341:843-8.

31 Sigalet DL, Lees GM, Aherne F, et al. The physiology of adaptation to small bowel resection in the pig: an integrated study of morphological and functional changes. $\mathcal{F}$ Pediatr Surg 1990;25:650-7.

32 Hines OJ, Bilchik AJ, Zinner MJ, et al. Adaptation of the $\mathrm{Na}^{+}$/glucose cotransporter following intestinal resection. $\mathcal{F}$ Surg Res 1994;57:22-7.

33 Shepherd RW, Gall DG, Butler DG, et al. Determinants of diarrhea in viral enteritis: the role of ion transport and epithelial changes in the ileum in transmissable gastroenteritis in piglets. Gastroenterology 1979;76:20-4.

34 Davidson GP, Gall DG, Petric M, et al. Human rotavirus enteritis induced in conventional piglets. F Clin Invest 1977; 60:1402-9.

35 Menge H, Sepulveda FV, Smith MW. Cellular adaptation of amino acid transport following intestinal resection in the rat. F Physiol 1983;334:213-23.

36 Horváth K, Hill ID, Devarajan P, et al. Short-term effect of epidermal growth factor (EGF) on sodium and glucose otransport of isolated jejunal epithelial cells. Biochim Biophys Acta Mol Cell Res 1994;1222:215-22.

37 Fedorak RN, Cheeseman CI, Thomson ABR, et al. Altered glucose carrier expression: mechanism of intestinal adaptation during streptozocin-induced diabetes in rats. Am $\mathcal{f}$ Physiol Gastrointest Liver Physiol 1991;261:G585-91. 